\title{
¿OФIA-SOPHIA
}

DOI: http://dx.doi.org/ 10.18634/sophiaj.13v.2i.739

\section{Ideal de servicio: orígenes de la inadecuación filosófica de la ingeniería}

\section{Service Ideal: Origins of the philosophical inadequacy of engineering}

Ideal de serviço: origens da inadequação filosófica da engenharia

Dany Mauricio González Parra* Diego Fernando Jaramillo Patiño** Álvaro González Osorio***

Información del artículo

Recibido: agosto de 2016 Revisado: octubre de 2016 Aceptado: junio de 2017

\section{Cómo citar:}

González, D.M., Jaramillo, D.F., González, A. Ideal de servicio: orígenes de la inadecuación filosófica de la Ingeniería. Sophia $13(2)$ : 40-45

El presente artículo es producto del proyecto de investigación "Filosofía de la ingeniería: un campo en construcción" código 765 de la Vicerrectoría de Investigaciones de la Universidad del Quindío. Proyecto desarrollado durante el periodo 2016-2017 y adscrito al grupo de investigación Razones y Acciones de la Universidad del Quindío.

* (E) PhD en Filosofía. Magíster en Filosofía. Docente del Programa de Filosofía de la Universidad del Quindío. Líder del grupo de investigación Razones y Acciones. Correo electrónico: dmgonzalez@uniquindio.edu.co

**Magíster en Filosofía. Docente del Programa de Ingeniería Electrónica de la Universidad del Quindío. Correo electrónico: diegojaramillop@ uniquindio.edu.co

***Magíster en Filosofía. Docente del Programa de Filosofía de la Universidad del Quindío. Correo electrónico: agonzalez@uniquindio.edu.co

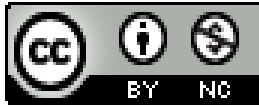




\title{
Resumen
}

La ingeniería, en tanto profesión, enfrenta la dificultad de compaginar su cuerpo de conocimientos con su ideal de servicio. Relación que se presenta clara en profesiones tradicionales como la medicina o el derecho. Esta inadecuación es una de las principales causas de la dificultad que se enfrenta a la hora de intentar definir ingeniería. En el presente trabajo se sostiene que el origen de la inadecuación está en la manera en la que se ha asumido que debe llevarse a cabo la reflexión en el campo de la ética de la ingeniería, la cual adolece de un fundamento axiológico y trasciende los currículos de los diferentes programas de ingeniería. Para respaldar lo planteado en el trabajo, (1) se analizan algunas de las principales definiciones de ingeniería, (2) se explica en qué consiste la inadecuación señalada, (3) se presenta la relación de esta inadecuación con la ausencia de una fundamentación axiológica de la reflexión alrededor de la ética de la ingeniería.

Palabras clave: Axiología, ética, ideal de servicio, ingeniería.

\begin{abstract}
Engineering, as a profession, faces the difficulty of combining its body of knowledge with its ideal of service; relation that is clear in traditional professions such as medicine or law. This inadequacy is one of the main causes of the difficulty that is faced when trying to define engineering. In the present work it is argued that the origin of the inadequacy lies in the way in which it has been assumed that it should be carried out the reflection in the field of engineering ethics, which lacks from an axiological foundation and transcends the curricula of the different engineering programs. In order to support what is stated in the paper, (1) some of the main definitions of engineering are analyzed, (2) it is explained the aforementioned inadequacy, (3) it is presented the relation of this inadequacy with the absence of an axiological foundation of the reflection around the ethics of engineering.
\end{abstract}

Keywords: Ethics, service ideal, inadequacy, axiology, engineering.

\section{Resumo}

A engenharia, enquanto profissão, enfrenta a dificuldade de conciliar seu corpo de conhecimentos com seu ideal de serviço. Relação que é clara em profissões tradicionais como medicina ou direito. Esta inadequação é uma das principais causas da dificuldade na hora de tentar definir a engenharia. Neste trabalho afirma-se que a origem da inadequação se encontra na forma em que se presume que deveria ser realizada a reflexão no campo da ética da engenharia, a qual carece de um fundamento axiológico e ultrapassa os currículos dos diferentes programas de engenharia. Para sustentar o proposto no trabalho, (1) são analisadas algumas das principais definições da engenharia, (2) se explica em que consiste a inadequação referida, (3) se apresenta a relação entre a inadequação e a ausência de uma fundamentação axiológica da reflexão em torno à ética da engenharia.

Palavras-chave: Ética, ideal de serviço, inadequação, axiologia, engenharia. 


\section{Introducción}

Durante el siglo XX, la ciencia se consolidó como legítimo objeto de investigación filosófica, tal como lo evidencian los trabajos de Popper, Carnap, Reichenbach, Kuhn, Feyerabend, Lakatos, Hacking, Suppes, Sneed, Moulines, entre otros. Algo similar ocurrió en torno a la tecnología (Durbin, 1991, 2007, 2010; Idhe, 1995). Caso contrario es el de la ingeniería. La reflexión filosófica alrededor de la ingeniería se ha reducido a referencias secundarias dentro de la filosofía de la ingeniería o de la tecnología o, a lo sumo, a cuestiones relacionadas exclusivamente con la ética: la ética de la enseñanza de la ingeniería y las dimensiones éticas de la ingeniería.

A la luz de este vacío, recientemente se ha observado la necesidad de que tenga lugar una mayor interacción entre filósofos e ingenieros. Esto, con el ánimo de establecer un campo de reflexión filosófica en ingeniería y consolidar una agenda de investigación coherente y compartida por la comunidad académica de ingeniería y de filosofía de la ingeniería. Es en este sentido en el que se propuso y desarrolló el proyecto de investigación "Filosofía de la Ingeniería: un campo en construcción". En este trabajo los investigadores nos propusimos mostrar que la filosofía de la ingeniería, a diferencia de la filosofía de la ciencia y la filosofía de la tecnología las cuales son disciplinas filosóficas profesionales bien establecidas-, es una disciplina filosófica profesional en construcción. Como evidencia del surgimiento de la ingeniería como objeto legítimo de reflexión filosófica, esto es, de la filosofía de la ingeniería como un campo real de la filosofía, mostramos que, en efecto, posee una comunidad académica, una agenda de investigación -problemas de corte ontológico, epistemológico, ético y social hacen parte de esta agenda emergente-, y órganos de difusión del trabajo científico, tales como publicaciones seriadas, foros, congresos, talleres, entre otros.

El impacto científico del trabajo desarrollado radica en dos aspectos, fundamentalmente, a saber: debido al desconocimiento casi total acerca del campo de la filosofía de la ingeniería en nuestro medio, presentarlo constituye ya un aporte significativo a los estudios filosóficos y de ingeniería en el país; además de que, dada su reciente aparición en el espectro internacional de la filosofía y de la ingeniería, el campo permite aportaciones nuevas. En cuanto a su impacto social, la reflexión acerca de los problemas filosóficos asociados a la ingeniería debe poder contribuir al mejoramiento efectivo de su práctica profesional, así como a la formación de nuevos ingenieros.
Es justo en relación con este último punto que tiene lugar el primer inconveniente la reflexión acerca de la ingeniería. La ingeniería, a primera vista, aparece como una profesión entre tantas otras. Sin embargo, en tanto profesión, enfrenta la dificultad de compaginar su cuerpo de conocimientos con su ideal de servicio. Relación que se presenta clara en profesiones tradicionales como la medicina o el derecho. Esta inadecuación es una de las principales causas de la dificultad que se enfrenta a la hora de intentar definir ingeniería. En el presente trabajo se sostiene que el origen de la inadecuación está en la manera en la que se ha asumido que debe llevarse a cabo la reflexión en el campo de la ética de la ingeniería, la cual adolece de un fundamento axiológico y trasciende los currículos de los diferentes programas de ingeniería. Para respaldar lo planteado en el trabajo, (1) se analizan algunas de las principales definiciones de ingeniería, (2) se explica en qué consiste la inadecuación señalada, (3) se presentan algunas de las reflexiones relacionadas con la formación ética de ingenieros y, finalmente, (4) se muestra por qué es necesaria una fundamentación axiológica de la reflexión alrededor de la ética de la ingeniería.

\section{¿Qué es ingeniería?}

Uno de los principales retos que representa la ingeniería para la reflexión filosófica es justamente su definición. ¿Qué es ingeniería? Es una pregunta cuya respuesta no resulta para nada fácil de conseguir. Esto, más allá de lo difundida que es la ingeniería misma como profesión. Uno de los principales aportes en función de hacer frente a este punto se encuentra en algunos de los trabajos de Carl Mitcham (2008; 2009).

Una de las primeras que recoge Mitcham se puede encontrar en la Enciclopedia de Ciencia y Tecnología McGraw-Hill (Parker, 2008), de acuerdo con la cual, ingeniería es el arte de "dirigir las grandes fuentes de energía de la naturaleza para el uso y conveniencia de los humanos". Una definición que, como bien señala el propio Mitcham, no dista mucho de la ofrecida por Tredgold quien la definió como "el arte de dirigir las grandes fuentes de energía de la naturaleza para el uso y conveniencia del hombre". Uno de los aspectos a resaltar de la definición de Tredgold es el matiz que supone poner al hombre como fin del quehacer ingenieril, que se ve resaltado por el contraste que representa el que luego no se hable de hombre sino de humanos. Es de resaltar porque evidencia, dada la connotación de hombre de la época, el que los beneficios de la ingeniería tenían como destinatarios a los dueños de los recursos y no a los humanos. Más allá de esto, 
la cuestión es que en casi dos siglos (la definición de Tredgold data de 1828) han permanecido dos ideas: (i) que la ingeniería es algo que se hace, llama la atención de que en ambas se haga alusión de su desarrollo como arte; y (ii) que la ingeniería es un arte cuyos productos deben estar al servicio de las personas, sean estas un conjunto delimitado de individuos o la humanidad en general.

Michael Davis (1998) mantiene el núcleo de estos dos elementos de la definición de ingeniería. No obstante, la noción de arte es desplazada por el conocimiento especializado que caracteriza al ingeniero. Así, de acuerdo con su propuesta, la ingeniería se caracteriza por (i) un conocimiento específico (especializado o técnico) y (ii) su compromiso de utilizar este conocimiento de una manera determinada. Esta manera determinada obedece, de acuerdo con Davis, a lo establecido en los códigos de ética de la ingeniería.

El mismo Davis (citado por Mitcham, 2009) ofrecerá una definición con un claro corte pragmático. De acuerdo con esta, un ingeniero no es otra cosa que un individuo que hace lo que hacen los ingenieros y que, en consecuencia, es reconocido por sus congéneres (otros ingenieros) como tal. Más allá de la circularidad de esta definición, la idea es que la ingeniería se reduce al grupo de personas históricamente constituido por personas que determinan lo que cuenta como ingeniería. Esto es, no hay una definición de ingeniería previa a la actividad ingenieril como tal, sino que a lo largo de la historia ha existido un grupo de individuos cuya labor se reconoce como ingeniería por otros individuos que hacen lo mismo y que se han identificado a sí mismos como miembros de tal comunidad.

De estas definiciones ya clásicas dentro de la reflexión sobre la ingeniería pueden extraerse varias conclusiones relacionadas con los intentos por definir la ingeniería; conclusiones que, como se verá en la próxima sección, tienen directa relación con lo que Mitcham llamara la inadecuación filosófica de la ingeniería. En primer lugar, las definiciones que ofrecen tanto Tredgold como Davis resaltan el carácter bipartito de toda profesión: el cuerpo de conocimiento y la destinación de ese conocimiento a su utilización de una determinada manera. De otra parte, y este es un aspecto común a las tres definiciones, aunque sea más evidente en la última de Davis, es la comunidad misma de ingenieros la que define qué es y qué no es ingeniería. En las dos primeras (Tredgold y Davis en 1998), la manera en la que se debe destinar el cuerpo de conocimiento está determinada por los códigos de ética de ingeniería; en la tercera (Davis en Mitcham, 2009), la comunidad de ingenieros.

\section{Inadecuación filosófica de la ingeniería}

La inadecuación de la que es acusada la ingeniería tiene un doble aspecto, cada uno relacionado con cada una de las definiciones antes presentadas. De un lado, hay una inadecuación que afecta a la ingeniería como profesión, esto es, a la relación entre el cuerpo de conocimiento que constituye su núcleo formativo y el ejercicio del ingeniero. Del otro, tal falencia o debilidad (Mitcham, 2008) tiene directa relación con la definición de ingeniería, y podría resumirse diciendo que el término a definir resulta incluirse de una u otra manera en la definición: ingeniería es lo que los ingenieros hacen y reconocen como su quehacer.

Como se anotó arriba, de acuerdo con una primera definición, la ingeniería se caracteriza por (i) un conocimiento específico (especializado o técnico) y (ii) su compromiso de utilizar este conocimiento de una manera determinada. Manera que obedece a lo establecido en los códigos de ética de la ingeniería. El conocimiento específico se ve representado por lo que en facultades y escuelas de ingeniería constituyen áreas como las matemáticas, la física, la biología, la química, etc. Áreas que históricamente son la columna vertebral de lo que se reconoce tanto desde el interior como desde el exterior de la ingeniería misma como el núcleo de la ingeniería. El compromiso relacionado con la utilización determinada de este conocimiento es lo que se ha dado a llamar ideal de servicio. Este ideal, tal como muestra el rastreo de Mitcham (2009), se ha asumido como el avance de los intereses comerciales e industriales, concepción propia de la época de Tredgold; luego, como su destinación al uso y conveniencia humanos; $\mathrm{y}$, finalmente, como directamente relacionado tanto con la salud, la seguridad y el bienestar de las futuras generaciones, como con los ideales de seguridad, salud y bienestar públicos.

Cualquiera sea la concepción del ideal de servicio que se adopte, la ingeniería tiene una inadecuación en su concepción: hay una evidente desconexión entre sus dos componentes. No es clara la relación entre el cuerpo de conocimientos y el ideal de servicio que, se supone, definen a la ingeniería. Es justo con base en esta brecha que Mitcham (2008) llama a los ingenieros a fortalecer (filosóficamente) su campo; llamado para el que utiliza como puntos de referencia profesiones bien establecidas y sin tal inadecuación como el derecho y la 
medicina (Goldberg, 2013). En el caso del derecho, por ejemplo, se reconoce con facilidad qué conocimientos debe adquirir el profesional: un abogado debe conocer los códigos y leyes del sistema dentro del cual debe desarrollar su labor. Este es el cuerpo de conocimientos del derecho. Por otra parte, su ideal de servicio es identificable con igual claridad: la administración de justicia.

El cuerpo de conocimiento del derecho está enmarcado en las leyes que sus profesionales deben conocer con el fin de administrarlas en la búsqueda de la justicia. Se puede decir que el periodo de formación de un abogado consiste en la profesionalización, la adquisición de maestría, por parte del estudiante de abogacía en el reconocimiento del conjunto de normas, leyes y códigos que permiten establecer qué es justo y qué no (al menos en términos procesales). No se desconoce en este punto la diferencia entre lo legal y lo justo, entendido este último concepto en lo que se podría denominar un sentido filosóficamente fuerte, sólo se atiende al hecho de que sea lo que sea que se entienda por justicia son los jueces (abogados) los encargados de administrarla, garantizarla. El caso de la medicina es similar. El periodo de formación de un estudiante de medicina consiste básicamente en el conocimiento del cuerpo humano con el fin de reconocer con el propósito de reconocer el cuerpo saludable, el que no lo es y promover el primero.

El derecho y la medicina no tienen mayor problema, pues, en cuanto a la relación que hay entre sus cuerpos de conocimiento y sus ideales de servicio. La relación entre unos y otros es más que clara. La situación de la ingeniería a este respecto, al contrario, está bien lejos de gozar de considerarse clara. La idea de lo que aparece a continuación es mostrar que esta inadecuación característica de la ingeniería tiene como una de sus principales razones la ausencia de reflexión de carácter axiológico, esto es, alrededor de los valores que guían el actuar de los ingenieros. Una reflexión que posibilite, fundamentalmente, dar claridad a la relación cuerpo de conocimientos-ideal de servicio en la ingeniería.

\section{Inadecuación en ingeniería: de origen axiológico}

De acuerdo con lo señalado arriba, el ideal de servicio de la ingeniería se ha asumido como el avance de los intereses comerciales e industriales; luego, como su destinación al uso y conveniencia humanos; y, finalmente, como directamente relacionado tanto con la salud, la seguridad y el bienestar de las futuras generaciones, como con los ideales de seguridad, salud y bienestar públicos (Mitcham, 2009). Sin embargo, no es clara la relación entre este ideal y el cuerpo de conocimientos de la ingeniería. El propósito en este apartado es señalar el que podría asumirse como uno de los orígenes, tal vez el principal, de la inadecuación señalada: la ausencia de una reflexión axiológica en el seno de la ingeniería misma. Esto es, una reflexión acerca de los valores que determinan el buen hacer ingenieril.

La ausencia de reflexión axiológica alrededor de la ingeniería se hace evidente en la limitación de este elemento en los planes de estudio a lo consignado en los diferentes códigos de ética. Si se tiene en cuenta el papel que juegan dentro de la definición de ingeniería tienen elementos como los de seguridad, salud y bienestar, puede ser comprensible que los diferentes códigos basen sus directrices en su aceptación (Copnia, 2003; Center for the Study of Ethics in the Professions); lo que no lo resulta es el hecho de que tanto estos códigos como las diferentes reflexiones adelantadas alrededor de ellos no lleven a cabo una fundamentación de lo que ha de entenderse por seguridad, salud o bienestar públicos (v.g.Takahara y Kajiwara, 2013; Schmidt, 2014; Han, 2015).

\section{Conclusiones}

La ausencia de fundamentación axiológica no es exclusiva de la ingeniería. Sin embargo, es justamente la importancia de su desarrollo así como lo complejo que aparenta ser su objeto lo que hace más acuciante llevar a cabo la misma. La razón por la que aquí se señala la necesidad de esta reflexión como paso inicial para enfrentar la señalada inadecuación descansa en la idea según la cual el buen desarrollo de cualquiera de las actividades humanas, y de manera especial las profesionales, depende de los valores relacionados con la actividad misma. Así como la belleza debe regir el accionar del artista, la salud el del médico y la justicia el del abogado, tendría que determinarse en qué consisten aquellos valores que determinan el correcto accionar del ingeniero, y este, en tanto profesional de la ingeniería, debe tener una idea clara acerca de estos.

Ya sea que se entienda valor como una cualidad irreal, como ente que funge de adjetivo de los objetos que se consideran bienes (Frondizi, 1958) o como la característica por la que un objeto es término de una actitud favorable (Villoro, 2012), lo único claro es que los valores y su estudio (la axiología) no se reduce a la ética o a los códigos de conducta. Por el contrario, la axiología es el fundamento de la ética misma, pero 
no solo de ella. La ingeniería y, en general, cualquier actividad humana se relaciona con una serie de valores cuya dimensión no se reduce a la ética o al apego a un código moral por parte de los sujetos que desarrollan tal actividad.

Es prácticamente imposible contemplar la posibilidad de determinar qué cuerpo de conocimientos contribuye de manera más adecuada a la realización de un ideal de servicio si no hay claridad acerca de ese ideal, constituido fundamentalmente por valores. De alguna manera, la conceptualización de la ingeniería ha avanzado a un ritmo diferente del que ha gobernado el desarrollo mismo de los currículos de las escuelas de ingeniería.

\section{Referencias bibliográficas}

Center for the Study of Ethics in the Professions. (s/f). Engineering. Illinois Institute of Technology. Recuperado de http://ethics.iit.edu/ecodes/ ethics-area/10

Consejo Profesional Nacional de Ingeniería - Copnia. (2003). Código de Ética para el ejercicio de la Ingeniería en general y sus profesiones afines y auxiliares. Recuperado de https://copnia.gov. co/codigo-de-etica-profesional/

Davis, M. (1998). Thinking Like an Engineer: Studies in the Ethics of a Profession. New York: Oxford University Press.

Durbin, P. (1991). Critical Perspectives on Nonacademic Science and Engineering. Bethlehem, PA.: Lehigh University Press.

Durbin, P. (2007). Philosophy of Techonology. Techné: Research in Philosophy and Technology, 10 (2), 101-131.

Durbin, P. (2010). Multiple Facets of Philosophy and Engineering. En van de Poel, I. y Goldberg, D. (Eds.) Philosophy and Engineering. An Emerging Agenda, 41-48. Dordrecht: Springer.
Frondizi, R. (1958). ¿Qué son los valores? México D. F Fondo de Cultura Económica.

Goldberg, D. (2013). Is engineering Philosophical Weak? En Michelfelder, D. McCarthy, N. y Goldberg, D. (Eds.) Philosophy and Engineering: Reflections on Practice, Principles and Process, 391-405. Dordbrecht: Springer.

Han, H. (2015). Virtue ethics, positive psycology, and a new model of science and engineering ethics education. Science an Engineering Ethics, 21, 441-460. DOI 10.1007/s11948-014-9539-7

Idhe, D. (1995). Philosophy of Technology, 1975-1995. Philosophy \& Technology, 1, ( 1 ), 1-8.

Mitcham, C. (2008). The philosophical weakness of engineering as a profession. En Goldberg, D. E. y McCarthy, N. (Eds.), Abstracts of the 2008 workshop on philosophy and engineering (WPE- 2008).

Mitcham, C. (2009). A Philosophical Inadequacy of Engineering. The Monist, 92 (3), 339-356.

Parker, S. (2008). Enciclopedia McGraw-Hill de Ciencia y Tecnología. México D. F. McGraw-Hill Interamericana.

Schmidt, A. (2014). Changing the paradigm for engineering ethics. Science and Engineering Ethics, 20, 985-1010. DOI 10.1007/ s11948-013-9491-y

Takahara, K., y Kajiwara, T. (2013). Engineering ethics education on the basis of continuous educaction to improve comunicationa ability. Electrical Engineering in Japan, 183 (3), 1-9.

Villoro, L. (2012). El poder y el valor: fundamentos de una ética política. México D. F.: Fondo de Cultura Económica. 